\title{
EDITORIAL
}

\section{Familiarity with the literature}

'If I have seen further it is by standing on the shoulders of giants'

\section{Sir Isaac Newton writing to Robert Hooke, 1675/6*}

Recently I have been working on an historical review of the development of the dietary fibre hypothesis. In this I have been trying to consider how the various strands of research in the past contributed to the scientific climate of opinion in the 1970 s into which the hypothesis was launched. In reading for this review it was very clear how much successive generations of researchers depended, often unknowingly, on the research that had gone before. At the same time it was disturbing to see how frequently experimental work was repeated and findings rediscovered and claimed as novel. This raised in my mind some thoughts on present trends in the scientific literature which I feel may be a cause for concern.

The pressures on space in scientific journals are considerable, as any author who has been asked to reduce the length of a paper will be aware. A trend that will unfortunately grow as the costs of producing a journal are very 'page-sensitive', both in the direct costs of publication and in distributing the journal to subscribers.

Phrases such as "it is no longer customary to introduce a paper with a detailed review of the literature' and 'references should be limited to those of direct relevance' appear in some form in many instructions to authors. These requirements do not, however, absolve authors of the responsibility of being familiar with the literature.

The growth in the number of journals means that familiarity with the literature can be very demanding and 'searching the literature' often means searching a database, the thoroughness of which depends on the choice of key words by both the searcher and the authors. Selecting key words for a paper can be seen as a chore imposed by the whim of a journal, but in fact it can make a crucial difference to the impact that a paper will have. The use of databases does mean that the older, pre-computer literature can be ignored by today's authors, who are denied the pleasure of serendipitous stumbling on key pieces of information when browsing through the journals directly. I also know from my own experience that the art of abstracting is not practised as diligently as it was before the photocopier became so convenient.

All of these factors work to reduce our awareness of the literature and more particularly of the concepts and models that the researchers in the past used as the basis for their research. I am sure that many authors share my feelings of indignation when a new paper ascribes beliefs to me that could not have been gleaned from reading what I actually wrote, even between the lines. Editors of journals with very rigid views of what constitutes a 'proper' scientific style are partly responsible in that an author's individuality can be edited out of a paper which in the process becomes rather anonymous. In this connection it is often very illuminating to read the older literature where, because of a more expansive style of writing, it is possible to read into the mind of the researchers.

I fear there is, however, a more sinister reason for not citing the work of others who laid the foundations for your work; this is the pressure to demonstrate that your findings are novel - as if your personal status would be diminished by recognizing the contribution of others. Scientific priority, of course, still retains some importance, but I believe that the

* Oxford Dictionary of Quotations, 1979, 3rd ed, p. 362. Oxford: Oxford University Press. 
status or impact of new observations or concepts is enhanced by such recognition in showing that the author is truly aware of the literature that constitutes the body of scientific knowledge of the subject in question.

My view is that we should recognize, as Newton did, that new insights are only possible because of the 'great and famous men and women' who established the foundations of our present knowledge.

The notion that many of our present techniques and experimental approaches are so much improved that they invalidate and supersede the work of the past does not bear critical examination. Our concepts and paradigms have evolved, and it is possible to reevaluate older experimental studies against these new concepts and gain new understanding, as is shown in the paper by Olsen \& Secher in this issue of the Journal.

D. A. T. Southgate 